Rapid Reviews COVID-19

\title{
Reviews of "The relationship between neighborhood poverty and COVID-19 mortality within racial/ethnic groups (Cook County, Illinois)"
}

Eyal Oren ${ }^{1}$, Adrienne Suazo ${ }^{2}$, Kate Pickett ${ }^{3}$

${ }^{1}$ San Diego State University Graduate School of Public Health, USA,

${ }^{2}$ San Diego State University/University of California, San Diego,

${ }^{3}$ University of York, Health Sciences, United Kingdom

Published on: Nov 16, 2020

DOI: $10.1162 / 2 \mathrm{e} 3983 f 5 . f 08 a 5 c 7 b$

License: Creative Commons Attribution 4.0 International License (CC-BY 4.0). 
To read the original manuscript, click the link above.

Summary of Reviews: This study adds to the literature on disparities in COVID-19 morbidity and mortality, though the data used may preclude some important, finergrained analyses of different sources of outcome disparities.

Reviewer 1 (Eyal Oren, Adrienne Suazo) |

Reviewer 2 (Kate Pickett) | प्र००

$$
\begin{aligned}
& \text { RR:C19 Strength of Evidence Scale Key. }
\end{aligned}
$$

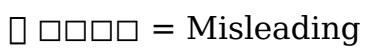

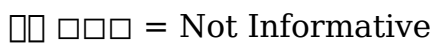

$$
\begin{aligned}
& \text { प्रा पि = Potentially Informative }
\end{aligned}
$$

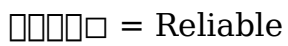

$$
\begin{aligned}
& \text { प्राप्र = Strong }
\end{aligned}
$$

To read the reviews, click the links below. 